\title{
How You Become Who You Are: A New Concept of Beauty for Plastic Surgery
}

\author{
Vittoradolfo Tambone', Mauro Barone ${ }^{2}$, Annalisa Cogliandro ${ }^{2}$, \\ Nicola Di Stefano ${ }^{1}$, Paolo Persichetti ${ }^{2}$ \\ 'Institute of Philosophy of Scientific and Technological Practice, ${ }^{2}$ Plastic and Reconstructive Surgery Unit, \\ Campus Bio-Medico University of Rome, Rome, Italy
}

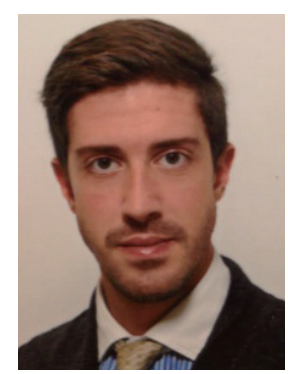

\section{INTRODUCTION}

The search for beauty and its value has been a discussion topic since the ancient Greeks composed their myths. The advent of safer and more advanced modern plastic surgery techniques and the spread of aesthetic medicine have renewed the search for beauty. Today, beauty seems possible, accessible, and more democratic than ever before [1]. To be beautiful is going to become an imperative, and from this standard, new and more subtle discriminations will arise: natural beauty will become more precious than artificial beauty, so that naturally beautiful bodies are privileged [2]. With regard to clinical practice, one of the most fundamental and interesting questions in aesthetic surgery is whether an objective indication exists for such procedures.

\section{THE ROLE OF EVIDENCE-BASED MEDICINE IN PLASTIC SURGERY}

Current considerations of different scientific paradigms in medicine have found evidence-based medicine (EBM) to be one of the stronger and more reliable paradigms, both from epistemological and practical perspectives [3]. EBM extends its claims over all fields of medical sciences, and therefore includes aesthetic surgery [4]. To effectively introduce EBM to aesthetic surgery, it is necessary to provide a valid notion of truth at a theoretical level which is able to ground the practical level [5]. A doctor must be able to specify the need for a procedure based on objective and sharable observations [6]; in other words, a diagnosis and intervention should never be performed based sole- ly on the physician's personal opinion or, even worse, the subjective desire of the patient [7]. Although in most ordinary clinical cases across the specialties of medicine, physicians are able to provide an adequately objective diagnosis and treatment, in aesthetic surgery, there seems to be a significant level of subjectivism [8]. Aesthetic surgeons often find themselves in the uncomfortable situation of being unable to offer valid scientific grounding for their procedures [9].

Facing this impasse, there are two possible ways forward: either we don't consider aesthetic surgery part of medical science, so it has to be removed from the profession of medicine and differently regulated, or we do consider aesthetic surgery to be medicine, and as a science, we would have to consider aesthetics in an objective and sharable way [10]. Beauty, as it is the central notion involved in the field of aesthetic surgery, must then contain an objective and sharable component. If this is the case, medicine will only consider the objective dimension of beauty, so that it could be scientifically treated, leaving those from other professions to judge cases in which no adequate clinical consideration is possible. If medicine has to be rational, the explanation of the concept of beauty is essential, because it represents the idea from which the physician's actions arise and towards which it must be oriented [11].

\section{WHAT IS BEAUTY?}

Before taking into account the notion of beauty in surgery, we will briefly examine the notion in philosophy.

The word "aesthetics" derives from the Greek aisthesis, which 
means "sensation". Starting from the root of aesthetics in sensation, it is necessary to capture its role within that complex experience which is evoked by sensation but cannot be definitely concluded within sensation.

Today, there is the occasion - and the need - to reflect on beauty in medicine as a subject within a branch of medicine, cosmetic surgery, which is growing every day. We will now present three different ways to answer to the eternal question: What is beauty? Subjectivism, objectivism, and relationism [12].

Subjectivists believe that the grounds for the experience of beauty are connected to the experience of the subject. Subjectivists are not necessary relativists; they only state that it is not possible to think about "beauty" as an inner property of an object. Objects' properties are, for example, shape, weight, color, and volume. Beauty must be something happening within the subject and which is aroused by the encounter with an object. In cosmetic surgery, such a subjectivist approach is considered a sort of "medicine of desires". Imagine a 22-year-old man going to a surgeon since he is not satisfied with his physique. He wonders whether he can have a face similar to one of his favorite actors, with a fascinating scar and a particular eye color. This choice regards only his desires, as there is no objective indication for this type of intervention.

On the opposing side, objectivism presents the notion of beauty starting from the material dimensions of the problem. Why is this specific object so beautiful? Language suggests to us the right way to solve this problem. We usually say, "This thing is beautiful," correctly specifying the reference to the object as the fundamental cause of our experience. Objectivism doesn't mean the universality of aesthetic appreciation. Not everybody has to like the same things, as pleasure can be disassociated from beauty. Objectivists only affirm that beauty arises from certain properties of the object: proportions, the harmony of parts, or the symmetry of elements. In surgery, this is an approach which searches for and nurses a pathological flaw. Imagine a 40-year-old man going to a plastic surgeon after an automotive pile-up in which he sustained a fracture to the nose; he would have never thought to visit a plastic surgeon before in his life. Rhinoplasty, in this case, is thus objectively necessary for the reinstatement of physiological breathing activity, which has been compromised.

\section{RELATIONISTIC VIEW OF BEAUTY}

Facing this simplistic alternative between subjectivism and objectivism, which apparently is irreconcilably dichotomous, the rational behavior is to pull back a little bit and to assert a relationistic position. Neither all in the object nor all in the subject, aesthetic experience involves two different moments: on the one hand, the subjective anxiety of the subject - on the other hand, the actual presence of something that generates the anxiety in the subject. Beauty arises from the match between the subjective element and the objective one, brought firmly together in the act of perception engaging them. According to the relationistic perspective, the experience of beauty arises from the relationship between the object and the subject. Consider for example a 32-year-old woman visiting a plastic surgeon because she suffers a hypertrophia on her nasal tip which makes it unaesthetic. Even though the flaw doesn't cause a breathing problem, the patient has suffered from problems building social relationships since her adolescence. Her nose has affected her social life and her psychological health. In this case, the patient's nose becomes a relationship problem, in which the subjective element comes out and settles on an objective deformity.

\section{THE NEW CONCEPT OF PLASTIC SURGERY}

Plastic surgery has to take care of the objective dimension of the problem and, as a branch of medicine, it has to take care of what is objectively known. Beauty is an emerging reality composed by objective, subjective, and relational dimensions, and medicine has to take care only of the objective part of the problem.

Beauty, in its complexity, deals with body morphology, which is objective and defines the exterior of the person. There are two realities, objective and subjective, which depend on this objective basis: the vision of the bodily "I" (how I see myself) and the perception of others about my body (how others see me). These two elements are subjective because they depend on subjective actions but, at the same time, they are also objective elements due to the subjects which are involved. "How I see myself" and "How I am seen” are crucial elements for everybody in relational life.

A relationistic vision of beauty does not confer any special role on the above elements (objective, subjective, and relational) in isolation, but it develops a notion which embraces them like they all have the same relevance. However, we also noted that the relationistic view has to take care of the objective element of the problem. If, in the investigation stage, we find out that the problem is not objective but regards only the subjective dimension, an adequate solution must be produced on the basis of other competencies of the medical team. This multidimensional vision of beauty, as a reality emerging from the three abovementioned dimensions, corresponds necessarily to a multidimensional way of solving the problems connected with beauty. That means active cooperation between the different specific competencies.

That is the reason why cosmetic medicine must be approached 


\section{Fig. 1. Theoretical algorithm}

Subjectivism, objectivism, and relationism.

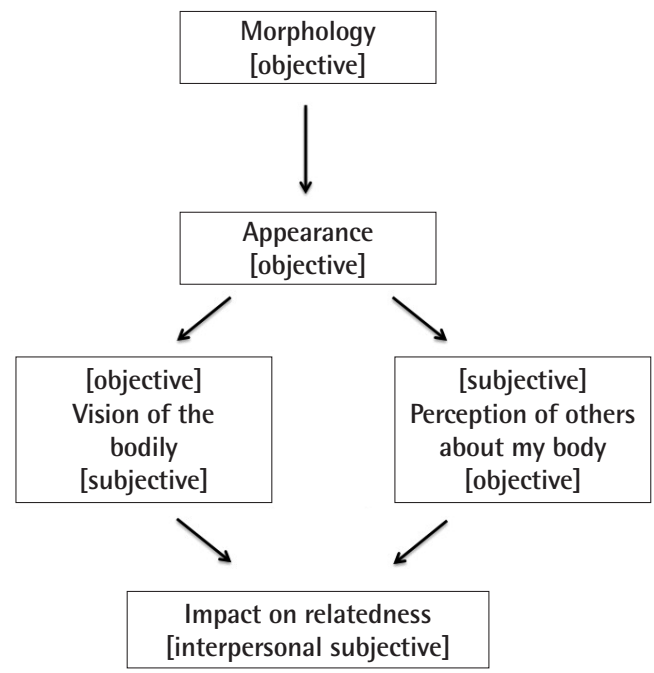

in a systemic way: Its actions produce feedback in other environments and the system as a whole reacts to its component actions. There is a need to guarantee an adequate follow-up to a plastic surgery operation because a single element always produces consequences throughout the whole system.

Morphology and appearance are objective. The perception of others about my body and the bodily vision involve both subjective and objective elements. Relatedness results from the contribution of the above elements (Fig. 1).

If medicine takes care of the objective dimension, this means that it has captured the objective elements of each study environment. Thus, medicine will take care of the "vision of the bodily 'I'” with the appropriate approach (e.g., psychological, psychiatric), starting from the objective part of the problem (Fig. 2).

\section{CONCLUSIONS}

Plastic surgery suffers from a fundamental dichotomy accepted too hastily as truth, and that should have been discussed or, at least, partially rethought. The difference between reconstructive surgery (often considered as the "therapeutic" and "noble" part of the specialization) and cosmetic surgery (often considered as the most commercial part) is simple. Consider, for example, the case of breast cancer. A breast surgeon operates to remove the cancer, and the plastic surgeon operates to reconstruct the breast. Only from an abstract point of view we can isolate the "strong" surgical moment (the removal of the cancer) from the "feeble", the cosmetic one (the reconstruction of the breast). The medical procedure is a unitary and systematic process, which can be considered as completed only at the end of the two important

\section{Fig. 2. Therapeutic algorithm}

How to act when faced with a patient request?

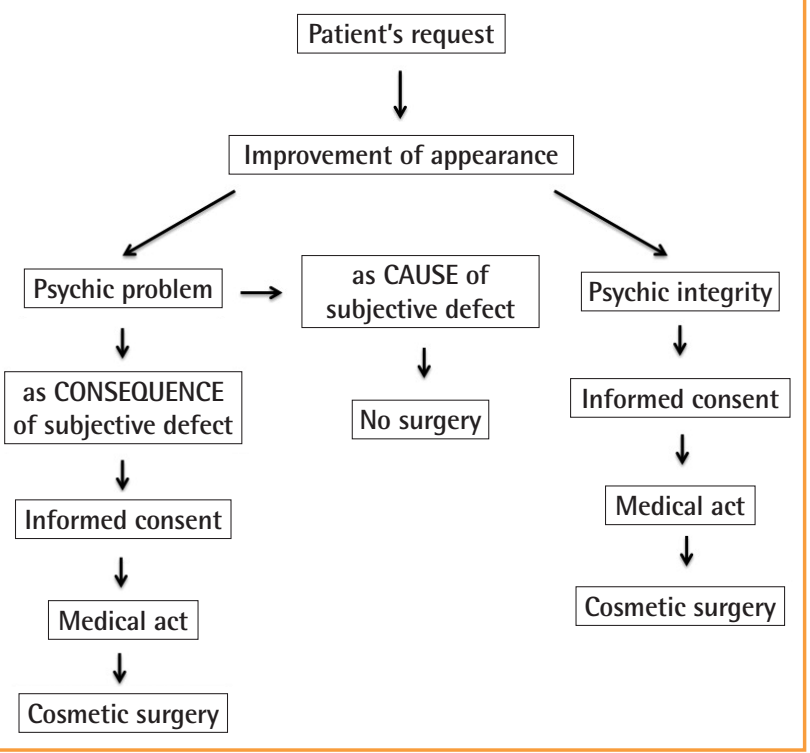

moments, first the removal of the weak part of the body, then giving back to the body its integrity. It is clear that the objective/ subjective or reconstructive/aesthetic are dichotomies that have to be surpassed. They produce misunderstanding or may even damage the purpose of plastic surgery.

The search for beauty doesn't have to be reduced to its subjective dimension or to a rush toward an ideal objective perfection. Beauty must improve the quality of life in general, in an attempt to surpass the physical and relational problems of the patient [13]. In this sense, cosmetic surgery doesn't exclusively answer to pathological desires but it contributes to the integral development of the person for these reasons: (1) It is necessary to consider beauty as an emerging reality composed of subjective, objective, and relational dimensions. (2) Cosmetic surgery doesn't represent an independent part of plastic surgery [14], but it is an essential element of it which is always in relationship with the reconstructive one [15].

The World Health Organization defines health as a state of complete physical, mental and social well-being. Health is not only the absence of any physical pathology, but it is considered a larger and more complex condition that encompasses various individual characteristics. Psychological disorders have to be carefully considered just like any other kind of pathology. In as much as plastic surgery can be considered a solution, it has to be considered an adequate therapeutic treatment.

As plastic surgeons, we must have a clear, objective, and sharable aesthetic concept, on which it is possible to lay the foundation of a new vision of cosmetic medicine recognized in systematic connection with other medical branches, with which it ac- 
tively cooperates in the planning, the definition, and the solution of the clinical problem.

\section{REFERENCES}

1. Scuderi N. A me la mela: dialoghi sulla bellezza, chirurgia plastica e medicina estetica. Milano, Italy: FrancoAngeli; 2011.

2. Persichetti P, Simone P, Tambone V. About beauty. Plast Reconstr Surg 2004;114:270-1.

3. Sackett DL, Rosenberg WM, Gray JA, et al. Evidence based medicine: what it is and what it isn't. 1996. Clin Orthop Relat Res 2007;455:3-5.

4. Chung KC, Swanson JA, Schmitz D, et al. Introducing evidence-based medicine to plastic and reconstructive surgery. Plast Reconstr Surg 2009;123:1385-9.

5. Pusic AL, Lemaine V, Klassen AF, et al. Patient-reported outcome measures in plastic surgery: use and interpretation in evidence-based medicine. Plast Reconstr Surg 2011;127: 1361-7.

6. Rohrich RJ. So you want to be better: the role of evidencebased medicine in plastic surgery. Plast Reconstr Surg 2010; 126:1395-8.

7. Kowalski E, Chung KC. The outcomes movement and evidence-based medicine in plastic surgery. Clin Plast Surg 2013; 40:241-7.

8. Drolet BC, Lorenzi NM. Registries and evidence-based medicine in craniofacial and plastic surgery. J Craniofac Surg 2012;
23:301-3.

9. Cheung MC, Allan BJ, Yang R, et al. Evidence-based medicine and its role in plastic surgery. J Craniofac Surg 2011;22: 385-7.

10. Waljee JF, Larson BP, Chung KC. Measuring treatment effectiveness: a guide to incorporating the principles of evidencebased medicine. Plast Reconstr Surg 2012;130:1382-94.

11. Persichetti P, Russo MT. Cosm-etica: chirurgia estetica, corpo e bellelezza. Milano: Mc Graw-Hill; 2012.

12. Tatarkiewicz W, Jaworska K. Storia di sei idee: l'arte il bello la forma la creatività l'imitazione l'esperienza estetica. Palermo: Aesthetica edizioni; 1993.

13. Mousavi SR. The ethics of aesthetic surgery. J Cutan Aesthet Surg 2010;3:38-40.

14. Lazzeri D, Larcher L, Nicoli F, et al. Ethics and the limits of science. Plast Reconstr Surg 2012;130:369e-370e.

15. Sterodimas A, Radwanski HN, Pitanguy I. Ethical issues in plastic and reconstructive surgery. Aesthetic Plast Surg 2011; 35:262-7.

Correspondence: Mauro Barone

Plastic and Reconstructive Surgery Unit, Via Alvaro del Portillo, 200-00128 Rome, Italy

Tel: +39-06-22541-1220, Fax: +39-06-22541-1936, E-mail: maurosabbarone@gmail.com

No potential conflict of interest relevant to this article was reported.

Received: 21 Jul 2015 • Revised: 9 Aug 2015• Accepted: 10 Aug 2015 pISSN: 2234-6163 - eISSN: 2234-6171

http://dx.doi.org/10.5999/aps.2015.42.5.517 • Arch Plast Surg 2015;42:517-520 